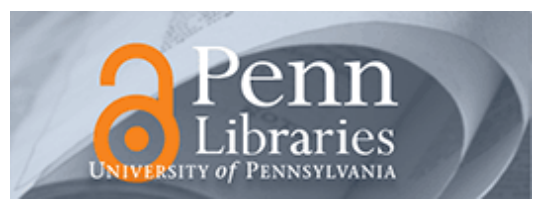

University of Pennsylvania ScholarlyCommons

October 2006

\title{
Carbide-Derived Carbons: Effect of Pore Size on Hydrogen Uptake and Heat of Adsorption
}

Gleb Yushin

Drexel University

Ranjan Dash

Drexel University

Jacek Jagiello

Quantachrome Instruments

John E. Fischer

University of Pennsylvania, fischer@seas.upenn.edu

Yury Gogotsi

Drexel University

Follow this and additional works at: https://repository.upenn.edu/mse_papers

\section{Recommended Citation}

Yushin, G., Dash, R., Jagiello, J., Fischer, J. E., \& Gogotsi, Y. (2006). Carbide-Derived Carbons: Effect of Pore Size on Hydrogen Uptake and Heat of Adsorption. Retrieved from https://repository.upenn.edu/ mse_papers/129

Postprint version. Published in Advanced Functional Materials, Volume 16, Issue 17, October 2006, pages 2288-2293.

Publisher URL: http://dx.doi.org/10.1002/adfm.200500830

This paper is posted at ScholarlyCommons. https://repository.upenn.edu/mse_papers/129

For more information, please contact repository@pobox.upenn.edu. 


\title{
Carbide-Derived Carbons: Effect of Pore Size on Hydrogen Uptake and Heat of Adsorption
}

\author{
Abstract \\ Cryoadsorption is a promising method of enhancing gravimetric and volumetric onboard $\mathrm{H}_{2} \mathrm{storage}$ \\ capacity for future transportation needs. Inexpensive carbide-derived carbons (CDCs), produced by \\ chlorination of metal carbides, have up to $80 \%$ open-pore volume with tunable pore size and specific \\ surface area (SSA). Tuning the carbon structure and pore size with high sensitivity by using different \\ starting carbides and chlorination temperatures allows rational design of carbon materials with enhanced \\ $\mathrm{C}-\mathrm{H}_{2}$ interaction and thus increased $\mathrm{H}_{2}$ storage capacity. A systematic experimental investigation of a \\ large number of CDCs with controlled pore size distributions and SSAs shows how smaller pores increase \\ both the heat of adsorption and the total volume of adsorbed $\mathrm{H}_{2}$. It has been demonstrated that \\ increasing the average heat of $\mathrm{H}_{2}$ adsorption above $6.6 \mathrm{~kJ} \mathrm{~mol}^{-1}$ substantially enhances $\mathrm{H}_{2}$ uptake at 1 atm \\ $(1 \mathrm{~atm}=101325 \mathrm{~Pa})$ and $-196^{\circ} \mathrm{C}$. The heats of adsorption up to $11 \mathrm{~kJ} \mathrm{~mol}^{-1}$ exceed values reported for metal-organic \\ framework compounds and carbon nanotubes.

\section{Keywords} \\ carbon, hydrogen storage, porous materials

\section{Comments} \\ Postprint version. Published in Advanced Functional Materials, Volume 16, Issue 17, October 2006, pages $2288-2293$. \\ Publisher URL: http://dx.doi.org/10.1002/adfm.200500830
}

This journal article is available at ScholarlyCommons: https://repository.upenn.edu/mse_papers/129 


\title{
Carbide-derived carbons: Effect of pore size on hydrogen uptake and heat of adsorption
}

\author{
By G. Yushin ${ }^{1}$, R. Dash ${ }^{1}$, J. Jagiello ${ }^{2}$, J. Fischer ${ }^{3}$, and Y. Gogotsi ${ }^{1 *}$ \\ ${ }^{1}$ Department of Materials Science and Engineering and A.J. Drexel \\ Nanotechnology Institute, Drexel University, Philadelphia, PA, 19104, USA \\ ${ }^{2}$ Quantachrome Instruments, 1900 Corporate Dr., Boynton Beach, FL, 33426, USA \\ ${ }^{3}$ Department of Materials Science and Engineering, University of Pennsylvania, \\ Philadelphia, PA, 19104, USA \\ *Correspondence to Y. Gogotsi: gogotsi@drexel.edu
}

Cryo-adsorption is a promising method of enhancing gravimetric and volumetric onboard $\mathrm{H}_{2}$ storage capacity for the future transportation needs. Inexpensive carbide-derived carbons (CDC), produced by chlorination of metal carbides, have up to $80 \%$ open pore volume with tunable pore size and specific surface area (SSA). Tuning the carbon structure and pore size with high sensitivity by using different starting carbides and chlorination temperatures allows rational design of carbon materials with enhanced $\mathrm{C}-\mathrm{H}_{2}$ interaction and thus increased hydrogen storage capacity. Systematic experimental investigation of a large number of CDC with controlled pore size distributions and SSA show how smaller pores increase both the heat of adsorption and the total volume of adsorbed $\mathrm{H}_{2}$. It has been demonstrated that increasing the average heat of $\mathrm{H}_{2}$ adsorption above $6.6 \mathrm{~kJ} / \mathrm{mol}$ substantially enhances $\mathrm{H}_{2}$ uptake at 1 atm and $-196{ }^{\circ} \mathrm{C}$. The heats of adsorption up to $11 \mathrm{~kJ} / \mathrm{mol}$ exceed values reported for metal-oxide framework compounds and carbon nanotubes.

\section{Introduction}

Hydrogen storage in solids occurs by physisorption, chemisorption and/or chemical reaction. Carbon-based materials have received considerable attention in the context of physisorption. ${ }^{[1]}$ Sorption processes require porous materials with a large number of sorption sites per unit mass or volume of an adsorbent, in other words materials with high specific surface area (SSA) (either gravimetric or volumetric) accessible to the sorbate. Many carbon structures with high SSA are known: activated carbon, exfoliated graphite, fullerenes, carbon nanotubes (CNT), nanofibers, etc. Investigations of hydrogen storage in carbons as a function of SSA have been reported over the last three decades, and activated carbons with SSA up to $\sim 3000 \mathrm{~m}^{2} / \mathrm{g}$ have been produced. ${ }^{[2]}$

Intuitively, hydrogen adsorption on carbons comprised of graphene sheets should depend linearly on SSA, and the concept has been generalized to CNT and to carbons 
lacking graphitic short-range order ${ }^{[1,3,4]}$ The amount of reversibly adsorbed hydrogen on nanostructured graphitic carbon at $-196{ }^{\circ} \mathrm{C}$ correlates with SSA for a large number of materials ranging from nanotubes to activated carbon (Fig. 1). It amounts to $\sim 1.1 \mathrm{wt} . \%$ per $1000 \mathrm{~m}^{2} / \mathrm{g}$ of SSA (Fig. 1). ${ }^{[3]}$ Since the SSA for two sides of a graphene sheet is $2620 \mathrm{~m}^{2} / \mathrm{g}^{[5]}-2965 \mathrm{~m}^{2} / \mathrm{g}^{[6]}, \sim 3 \mathrm{wt} . \%$ appears to be the limit for low-temperature, ambient pressure storage. This, along with low measured hydrogen uptake at room temperature, ${ }^{[3,}$ 7] and numerous errors in the measurements of hydrogen uptake by carbon nanostructures, led to loss of confidence in carbon's potential for hydrogen storage.

This pessimism may have been premature. The data in Fig. 1 were obtained from samples with different surface chemistry, structure and graphene curvature. While these differences are generally ignored ${ }^{[3]}$ it is well known in adsorption science that parameters other than SSA may strongly influence the sorbent properties. ${ }^{[8]}$ Fig. 1 supports this statement by demonstrating large variations in $\mathrm{H}_{2}$ storage capacities in samples with similar SSA. Clearly, in order to maximize the $\mathrm{H}_{2}$ sorption at the desired temperature (T) and pressure $(\mathrm{P})$ one needs not only to maximize the number of the adsorption sites per unit mass and volume of the solid (which could indeed be proportional to SSA) but also tune the $\mathrm{H}_{2}$ - solid interaction energy that would allow more sorption sites to adsorb $\mathrm{H}_{2}$ molecules. Optimizing the adsorbent structure for increased adsorption per SSA is at least as important as maximizing SSA. If all the pores in high SSA materials were filled with adsorbed $\mathrm{H}_{2}$, a very high gravimetric $\mathrm{H}_{2}$ storage would be possible. Fig. 2 shows the maximum possible $\mathrm{H}_{2}$ uptake as a function of pore volume calculated for complete pore filling by either solid or liquid hydrogen. Porous carbons with pores occupying $78 \%$ or more of the volume (pore volume $\sim 1.6 \mathrm{cc} / \mathrm{g}$ ) could potentially exceed the long-term target of the US Department of Energy of $10 \mathrm{wt} . \%$ if the $\mathrm{H}_{2}-\mathrm{C}$ interaction were optimized. This observation justifies further studies on carbon materials to design efficient hydrogen sorbents.

Gas adsorption takes place when the interaction energy between an adsorbate molecule and adsorbent is equal to the work needed to bring a free molecule to the adsorbed state at a given temperature. Most theories approximate the adsorbed state as the saturated pressure $\left(\mathrm{P}_{0}\right)$ state. At this approximation, for a given $\mathrm{T}$ and $\mathrm{P}$ one can calculate the work needed for an average molecule to be adsorbed. As such, one can either determine at what $\mathrm{P}$ most molecules get adsorbed when the interaction energy and $\mathrm{T}$ are known, or estimate the interaction energy for gas molecules to be adsorbed at the desired $\mathrm{P}$ and $\mathrm{T}$. Surprisingly little experimental research has been done on the parameters that influence the $\mathrm{H}_{2}$ - sorbent interaction potential. There remains a lack of understanding of the relation between the surface chemistry, microstructure, and porosity of carbon and its interaction with $\mathrm{H}_{2}$ molecules. There have been only a few systematic studies, mostly theoretical, of the effects of pore size on the carbon- $\mathrm{H}_{2}$ interaction. ${ }^{[9-13]}$. Very recent calculations ${ }^{[13]}$ show that the heat of adsorption of hydrogen on "ideal" adsorbent should be $\sim 15 \mathrm{~kJ} / \mathrm{mol}$, if both the delivery and storage is to occur at room temperature. This value is considerably higher than the average heat of adsorption of hydrogen on activated carbons and CNT $(5-6.5 \mathrm{~kJ} / \mathrm{mol})$ as well as on MOF $(0-7 \mathrm{~kJ} / \mathrm{mol})$.

We recently reported ${ }^{[14]}$ the effect of pore size on the $\mathrm{H}_{2}$ sorption and demonstrated an increased $\mathrm{H}_{2}$ uptake in materials with smaller pores. In particular, we showed that the pore width of $\sim 0.6 \mathrm{~nm}$ could be the optimum for $\mathrm{H}_{2}$ storage. Here we 
present a detailed analysis of the mechanisms of $\mathrm{H}_{2}$ storage to provide guidance for future material development.

The sorption experiments were performed mainly on porous carbons prepared by high temperature chlorination of carbides, referred to as carbide-derived carbons (CDC). ${ }^{[15]}$ Our choice of this class of porous carbons was determined by the ability to finely tune the pore size distribution by controlling the parameters of the synthesis process. ${ }^{[15,16]}$ In addition, CDC are known to have a high SSA and tunable pore volume, and many of the precursor carbides are inexpensive. ${ }^{[15]}$ The discussed properties of CDC make it not only a good material for fundamental studies, but also a promising candidate for gas storage applications.

\section{Results and Discussion}

\subsection{Structure and porosity}

Selective removal of metals from metal carbides results in the formation of porous carbon with a density lower than that of graphite. In the 1960s, CDC were produced as a byproduct of metal chloride synthesis according to the reaction

$\mathrm{MeC}+x / 2 \mathrm{Cl}_{2}=\mathrm{MeCl}_{x}+\mathrm{C}$,

where $\mathrm{Me}$ is a carbide forming metal. At that time, $\mathrm{CDC}$ was considered to be an undesirable by-product and it was periodically burned in the reactor to increase the chloride production rate. ${ }^{[15]}$

Pore size of CDC is influenced by the spatial distribution of carbon atoms in the precursor carbide, the synthesis temperature, the size of the chloride molecules, the presence of catalytic particles and the effect of optional post-treatments, such as purification or activation. ${ }^{[15]}$ Fig. 3 shows the pore size distributions (PSD) of CDCs derived from $\mathrm{TiC}, \mathrm{ZrC}, \mathrm{B}_{4} \mathrm{C}$, and $\mathrm{SiC}$ chlorinated at different temperatures. Low temperature $\left(<600^{\circ} \mathrm{C}\right)$ generally results in very uniform pore size. PSDs are narrower than those measured from single-walled carbon nanotubes and typical activated carbons, and are comparable to zeolites. Increasing synthesis temperature leads to pore enlargement and broader PSDs. Some samples were annealed in hydrogen for two hours at $600^{\circ} \mathrm{C}$ to remove residual chlorine trapped in nanopores during synthesis. This procedure resulted in increased SSA and micropore volume accessible to argon. Opening of small pores and shifting the pore size distribution to smaller values was also generally observed (data not shown).

A gradual evolution of CDC structure as the chlorination temperature increases was revealed by Raman spectroscopy, X-Ray diffraction (XRD) ${ }^{[17-20]}$, and TEM (Fig. 4). At low synthesis temperatures, CDC consist of amorphous carbon with no distinguishable graphite fringes (Fig. 4a). As the synthesis temperature increases to about $800^{\circ} \mathrm{C}$ (Fig. $4 \mathrm{~b}$ ), most $\mathrm{CDC}$ (including those obtained from $\mathrm{B}_{4} \mathrm{C}, \mathrm{TiC}$, and $\mathrm{ZrC}$ ) re-organize into highly curved single graphene sheets (fullerene-like structures). At even higher temperatures, curved thin graphite ribbons with an interplanar distance of $\sim 0.34 \mathrm{~nm}$ appear in the TEM micrographs (Figs. 4c and d). Amorphous carbon is still present in these samples but in a considerably smaller quantity. In contrast to other CDC, SiCderived CDC remain amorphous up to $1200^{\circ} \mathrm{C} .{ }^{21]}$ Changes in CDC microstructure are inherently connected to changes in pore structure. Amorphous structures formed at lower temperatures are clearly associated with uniform and relatively small pores, whereas 
graphitic ribbon network structures formed at higher synthesis temperatures are linked to less uniform and generally larger pores (compare Figs. 3 and 4).

\subsection{Hydrogen sorption}

Plotting the $\mathrm{H}_{2}$ adsorption capacity of carbon surfaces as a function of the average pore size ${ }^{[14]}$ clearly defines the trend of increasing storage with decreasing pore size. However, the experimental data are scattered because materials with different PSD's may have the same average pore size. In order to separate the contributions of larger and smaller pores, we plotted separately the $\mathrm{H}_{2}$ uptake as a function of volume and SSA of pores below and above $1 \mathrm{~nm}$ (Fig. 5) and found a linear increase for pores smaller $1 \mathrm{~nm}$ (Figs. 5a, b). Small deviations from linearity occur in materials which have high additional SSA associated with pores larger than $1 \mathrm{~nm}$. A large volume of larger pores may contribute significantly at $1 \mathrm{~atm}$, in spite of their lower efficiency. In a similar plot for $\mathrm{H}_{2}$ uptake at $0.1 \mathrm{~atm}$, where a stronger interaction is needed for $\mathrm{H}_{2}$ adsorption and therefore the contribution from large pores should be further diminished, these deviations tend to disappear (Fig.6). In contrast, we find no correlation between total $\mathrm{H}_{2}$ uptake and volume and SSA of larger pores (Figs. 5c,d). This supports our previous results ${ }^{[14]}$ and also explains the origin of the large data scattering observed in Fig. 1. Comparison of the observed uptake and the maximum amount of $\mathrm{H}_{2}$ able to fill all the pores $<1 \mathrm{~nm}$ (solid line in Fig. 5a), suggests that, independent of other parameters, smaller pores are nearly completely filled with adsorbed $\mathrm{H}_{2}$ at $-196^{\circ} \mathrm{C}$ and 1 atm.

Smaller pores are clearly more efficient in $\mathrm{H}_{2}$ sorption due to stronger interaction with $\mathrm{H}_{2}$ molecules. The total interaction between the adsorbate molecule and a solid is greater if the molecule can interact with a larger number of surface atoms, as happens in small curved pores (Figs. 4 a,b) or narrow slit pores. When a molecule is located in a slit pore, the sorbate-sorbent interaction potentials from both sides of the pore wall overlap to a degree determined by the pore width. A good illustration is the known decrease of the threshold pressure for Ar adsorption with decreasing pore size. ${ }^{[8]}$ While such an influence has rarely been discussed in papers on hydrogen storage, the phenomenon is well known. In fact, nearly all gas sorption theories employed in the software supplied with commercial instruments to derive PSDs from sorption isotherms take it into account. One should always expect a stronger interaction if the molecule is placed inside a small pore as compared to a larger one, or to an exterior solid surface, such as basal plane of graphite or outer surface of a single nanotube.

The opening of additional small pores in CDC by annealing in hydrogen led to a higher $\mathrm{H}_{2}$ sorption capacity, with values up to $336 \mathrm{cc} / \mathrm{g}(3.0 \mathrm{wt}$. \%) as shown in Fig. 7. Hydrogen treatment increased the storage by as much as $75 \%$ for some materials. This clearly shows the effect of pore accessibility on the sorption of hydrogen by porous carbons. The superior performance of CDC as compared to that of SWCNT, MWCNT and metal-organic frameworks (MOF-5) at ambient pressure has been shown in Ref. ${ }^{[14]}$ CDCs can store over twenty percent more $\mathrm{H}_{2}$ than advanced MOF ( $\sim 1.3$ wt. $\%$ in MOF-5 [14]; $\sim 1.4$ wt. $\%$ in $\mathrm{Cu}_{3}(\mathrm{BTC})_{2}\left(\mathrm{H}_{2} \mathrm{O}\right)_{3}{ }^{[22]} ; \sim 2 \mathrm{wt} . \%$ in $\left[\mathrm{Co}_{3}(\mathrm{bpdc})_{3} \mathrm{bpy}\right] \cdot 4 \mathrm{DMF} \cdot \mathrm{H}_{2} \mathrm{O}^{[23]}$; 2.48 wt. $\%$ in MOF-505 $\left.{ }^{[24,25]}\right)$ and several times that of CNT $\left(<0.9\right.$ wt. $\left.\%{ }^{[14]}\right)$. They also outperform low temperature metal hydrides ${ }^{[26]}$. Since SWCNT and most MOF have SSA comparable to or greater than $\mathrm{CDC}$, the observed uptake variations could be explained by the presence of a narrow distribution of small pores in CDC. However, the strength of interaction between $\mathrm{H}_{2}$ and sorbent may be another important factor. 
Heat of $\mathrm{H}_{2}$ adsorption on CDC calculated for selected materials characterizes the interaction between $\mathrm{H}_{2}$ and carbon. Stronger interactions should result in a higher $\mathrm{H}_{2}$ coverage of the sorbent surface, if $\mathrm{H}_{2}$ sorption sites are available. Fig. 8 demonstrates the experimentally observed increase in $\mathrm{H}_{2}$ uptake at $1 \mathrm{~atm}$. and $-196{ }^{\circ} \mathrm{C}$ per surface area as the integrated average heat of adsorption grows, in agreement with theoretical calculations ${ }^{[13]}$. For $\mathrm{H}_{2}$ adsorption at room temperature, a larger heat of adsorption is required due to the higher kinetic energy of $\sim 3.6 \mathrm{~kJ} / \mathrm{mol}$ and the larger work needed to adsorb an average molecule. So far, $\mathrm{CDC}$ heats of $\mathrm{H}_{2}$ adsorption noticeably exceed those of MOFs and CNTs (Fig. 9). Selected sorption sites in the CDC demonstrated $\mathrm{H}_{2}$ heat of adsorption in access of $8 \mathrm{~kJ} / \mathrm{mol}$. To the best of our knowledge, such high experimental values have not been reported for carbon-based adsorbents before. ${ }^{[27]} \mathrm{CDC}$ with smaller pores systematically shows a considerably stronger $\mathrm{C}-\mathrm{H}_{2}$ interaction.

While we observed a correlation between the $\mathrm{H}_{2}$ adsorption and pore size in CDC, we cannot exclude the possibility that other parameters of carbon microstructure, such as pore shape or degree of disorder or internal surface chemistry, may influence sorption properties as well. For a given pore size (minimum pore dimension), cylindrical and spherical pores may result in a different total sorbate-sorbent interaction as compared to slit-shape pores. In addition, different sorption sites may exhibit variations in interaction potentials due to the differences in the arrangement of neighboring atoms or directionality and type of bonding. It is well known that graphite orientation strongly influences its ability to adsorb electrolyte ions on the surface: edge planes of graphite exhibit up to 70 times higher specific capacitance as compared to the basal planes under identical conditions. ${ }^{[28]}$ Gas sorbates may exhibit similar site or orientation dependence. In addition, surface functionalities, impurities or dopants are more likely to be attached to the edges of the graphitic planes. Greater disorder (higher percentage of carbon edge atoms) may result in a stronger influence of carbon surface chemistry on $\mathrm{H}_{2}$ sorption properties. While some carbon nanomaterials such as carbon nanotubes mostly have basal planes of graphite exposed to a sorbate gas, highly porous activated carbons and CDC exhibit a high percentage of edge plane atoms available for $\mathrm{H}_{2}$ sorption. The presence of trace metal atoms in CDC of up to 0.5 at. \% could also potentially play a role in $\mathrm{H}_{2}$ uptake and heat of adsorption, as theoretically predicted and demonstrated in several recent publications ${ }^{[29-30]}$.

In general, our results are in fairly good agreement with literature data for activated carbons. ${ }^{[3,31]}$ Porous carbons with a large volume of small pores show a high uptake of $\mathrm{H}_{2}$, while carbons with a high SSA, but larger pores demonstrate a moderate $\mathrm{H}_{2}$ capacity. On the other hand, differences in chemical composition and structure between $\mathrm{CDC}$ and activated carbons may cause some differences in the $\mathrm{H}_{2}$ heat of adsorption and storage capacity.

While high gravimetric hydrogen uptake can be achieved in CDC, it is important to underscore CDC's principal advantage in volumetric uptake of hydrogen compared to all other carbons. All powdered, pelletized or pressed activated carbons contain $40 \%$ or more of macropores as space between micron-sized particles, which cannot contribute to storage by physisorption. Conversely, CDC produced from bulk ceramics ${ }^{[32]}$ have no macroporosity, thus almost $100 \%$ of the pore volume contributes to hydrogen storage. Volumetric capacity enhancements of about $40 \%$ can be realized compared to other carbons with the same micropore size/volume. Thus, gas tanks filled with densely packed 
CDC plates or bricks may provide the maximum volumetric storage of hydrogen. The 0.8 $\mathrm{g} / \mathrm{cc}$ density of the bulk CDC with the $3 \mathrm{wt}$. \% gravimetric capacity translates into 24 $\mathrm{kg} / \mathrm{m}^{3}$ volumetric capacity.

\section{Summary}

Optimized CDC have the potential to meet the needs of a hydrogen economy. $\mathrm{CDC}$ with gravimetric hydrogen storage density up to $3.0 \mathrm{wt} \%$ and volumetric density up to $24 \mathrm{~kg} / \mathrm{m}^{3}$ at $1 \mathrm{~atm}$ pressure and $-196{ }^{\circ} \mathrm{C}$, have demonstrated a higher volumetric and gravimetric storage capacity compared to MOF, SWCNT, MWCNT and low temperature metal hydrides. These values are believed to be due to smaller average pore size and higher average heat of $\mathrm{H}_{2}$ adsorption in selected $\mathrm{CDC}$ samples. Considering that less than half the total CDC pore volume accessible to argon is currently used by hydrogen at ambient pressure, there is great potential for increased storage density by increasing pressure or by further tuning the PSDs. While small pores (1 nm or below) are efficient for hydrogen sorption, pores above $1 \mathrm{~nm}$ do not contribute much to storage of hydrogen at ambient pressure and liquid nitrogen temperature.

\section{Experimental}

Material synthesis: We synthesized CDC from commercially available powders of $\mathrm{B}_{4} \mathrm{C},{ }^{[17]} \mathrm{ZrC},{ }^{[18]} \mathrm{TiC}^{[20]}$ and $\mathrm{SiC}^{[19]}$ at various temperatures in the $400-1200^{\circ} \mathrm{C}$ range. $\mathrm{TiC}, \mathrm{ZrC}$ and $\mathrm{B}_{4} \mathrm{C}$ with the average particle size of $\sim 2-4 \mu \mathrm{m}$ were obtained from Alfa Aesar, while $\beta$-SiC powder with the average particle size of $\sim 2 \mu \mathrm{m}$ was obtained from Superior Graphite. Chlorination experiments were performed on as-received samples using high purity chlorine (BOC Gases, UHV grade) and argon (BOC Gases, UHV grade) as reactive and purging gases, respectively. For CDC synthesis, selected carbide powder was placed onto a quartz sample holder and loaded into the hot zone of a horizontal quartz tube furnace. The tube was Ar purged for 30 minutes before heating at a rate of $\sim 30^{\circ} \mathrm{C} / \mathrm{min}$ to the desired temperature. Once the desired temperature was reached and stabilized, the Ar flow was stopped and a 3-hour chlorination began in $\mathrm{Cl}_{2}$ flowing at a rate of $10 \mathrm{sccm}$. After the completion of the chlorination process, the samples were cooled down under a flow of Ar to remove residual metal chlorides from the pores, and taken out for further analyses. In order to avoid a back-stream of air, the exhaust tube was connected to a bubbler filled with sulfuric acid. A detailed description of the chlorination apparatus used in this study can be found in Ref. ${ }^{[15]}$

Characterization and $\mathrm{H}_{2}$ sorption measurements: The structure of the $\mathrm{CDC}$ was investigated using high-resolution transmission electron microscopy (HRTEM). The TEM samples were prepared by a 2-min. sonication of the CDC powder in isopropanol and deposition on the lacey-carbon coated copper grid (200 mesh). A field-emission TEM (JEOL 2010F, Japan) with an imaging filter (Gatan GIF) was used at $200 \mathrm{kV}$.

Porosity and $\mathrm{H}_{2}$ sorption properties of $\mathrm{CDC}$ were studied using an automated micropore gas analyzer Autosorb-1 (Quantachrome Instruments, USA). The Ar sorption isotherms collected at liquid nitrogen temperature $\left(-196{ }^{\circ} \mathrm{C}\right)$ were analyzed using Brunauer, Emmet, Teller (BET) equation and non-local density functional theory $(\mathrm{NLDFT})^{[33-38]}$ to reveal the SSA and pore-size distributions (PSD) of CDC. Quantachrome's data reduction software Autosorb v.1.27 ${ }^{[31]}$ was employed for these calculations. The weighted pore size of the CDC was calculated from the pore-size 
distribution using numerical integration of $\frac{\int_{0 n m}^{7 n m} w V d w}{\int_{0 n m}^{7 n m} V d w}$, where $w$ is the pore width and $V$ is the differential pore volume. $\mathrm{H}_{2}$ sorption measurements were performed at $-196{ }^{\circ} \mathrm{C}$ and selectively at liquid argon temperature $\left(-186{ }^{\circ} \mathrm{C}\right)$. Gravimetric storage density of $\mathrm{H}_{2}$ (wt.\%) was defined as $\left(\rho_{\text {Hydrogen }} . v_{\text {Hydrogen }} .100\right)$, where $\rho_{\text {Hydrogen }}$ is the hydrogen density; $v_{\text {Hydrogen }}$ is the volume of $\mathrm{H}_{2}$ adsorbed at $-196{ }^{\circ} \mathrm{C}$ and $1 \mathrm{~atm}$ in a unit mass of CDC. This definition is currently very common in publications on $\mathrm{H}_{2}$ sorption, but it gives slightly higher values compared to the one, where the mass of adsorbed gas is normalized by the total mass of adsorbent / adsorbate system. The density of bulk CDC was defined as the mass to geometrical volume ratio. To reveal the influence of pore size on the $\mathrm{H}_{2}$-cabron interaction, $\mathrm{H}_{2}$ sorption measurements on a series of CDC samples at both cryogenic temperatures were analyzed using Clausius-Clapeyron equation: $\left[\begin{array}{ll}8, & 37,38\end{array} Q_{s t}=\right.$ $\frac{\operatorname{R.\ell n}\left(P_{87.4} / P_{77.3}\right)}{(1 / 77.3-1 / 87.4)}$, where $Q_{s t}$ is the heat of adsorption, $R$ is a real gas constant; $P_{87.4}$ and $P_{77.3}$ are $\mathrm{H}_{2}$ pressures obtained from B-Spline fitted hydrogen isotherm at liquid argon and liquid nitrogen temperatures, respectively.

\section{Acknowledgement}

This work was supported by the US Department of Energy under grant No. DEFC36-04GO14282 via the University of Pennsylvania. HRTEM studies were performed in Penn Regional Nanotechnology Facility, University of Pennsylvania. Additional material characterization was performed in Drexel University Centralized Materials Characterization Facility. We are thankful to G. Laudisio and T. Yildirim for helpful discussions.

[1] M.G. Nijkamp, J.E.M.J. Raaymakers, A.J. van Dillen, and K.P. de Jong, Appl. Phys. A., 2001, 72, 619.

[2] D. Lozano-Castello, D. Cazorla-Amoros, and A. Linares-Solano, Energy \& Fuels, 2002, 16, 1321.

[3] L. Schlapbach and A. Zuttel, Nature, 2001, 414, 353.

[4] A. Zuttel, P. Sudan, P. Mauron, T. Kiyobayashi, C. Emmenegger, and L. Schlapbach, International Journal of Hydrogen Energy, 2002, 27, 203.

[5] K.R. Matranga, A.L. Myers, and E.D. Glandt, Chem. Eng. Science, 1992, 47, 1569.

[6] H.K. Chae, D.Y. Siberio-Pe'rez, J. Kim, Y. Go, M. Eddaoudi, A.J. Matzger, M. O'Keeffe, and O.M. Yaghi, Nature, 2004, 427, 523.

[7] H. Kajiura, S. Tsutsui, K. Kadono, M. Kakuta, M. Ata, and Y. Murakami, Appl. Phys. Letters, 2003, 82, 1105.

[8] R.T. Yang, "Adsorbents: fundamentals and applications", Wiley-Interscience, Hoboken, NJ, US 2003. 
[9] M. Rzepka, P. Lamp, and M.A. de la Casa-Lillo, J. Phys. Chem. B, 1998, 102, 10894.

[10] M.A. de la Casa-Lillo, F. Lamari-Darkrim, D. Cazorla-Amoros, and A. LinaresSolano, J. Phys. Chem. B, 2002, 106, 10930.

[11] Q.Y. Wang and J.K. Johnson, J. Chem. Phys., 1999, 110, 577.

[12] N. Texier-Mandoki, J. Dentzer, T. Piquero, S. Saadallah, P. David, and C. VixGuterl, Carbon, 2004, 42, 2744.

[13] S.K. Bhatia and A.L. Myers, Langmuir, 2006, 22, 1688-1700.

[14] Y. Gogotsi, R.K. Dash, G. Yushin, T. Yildirim, G. Laudisio, and J.E. Fischer, J. Am. Chem. Soc., 2005, 127 (46), 16006-16007.

[15] G. Yushin, Y. Gogotsi, and A. Nikitin, "Carbide Derived Carbon, in Nanomaterials Handbook”, (Ed: Y. Gogotsi), CRC Press, US, 2005, Ch.8., 237.

[16] Y. Gogotsi, A. Nikitin, H. Ye, W. Zhou, J.E. Fischer, B. Yi, H.C. Foley, and M.W. Barsoum, Nature Materials, 2003, 2, 591.

[17] R.K. Dash, A. Nikitin, and Y. Gogotsi, Microporous and Mesoporous Materials, 2004, 72, 203.

[18] R.K. Dash, G. Yushin, and Y. Gogotsi, Microporous and Mesoporous Materials, 2005, 86, 50 .

[19] D.A. Ersoy, M.J. McNallan, and Y. Gogotsi, "High Temperature Chlorination of SiC for Preparation of Tribological Carbon Films", in Proceedings of the Symposium on High Temperature Corrosion and Materials Chemistry,v. 98-9, (Eds: P.Y. Hou, M.J. McNallan, R. Oltra, E.J. Opila, and D.A. Shores), The Electrochemical Society, Inc.: Pennington, NJ, US, 1998, 324.

[20] R.K. Dash, J. Chmiola, G.N. Yushin, Y. Gogotsi, G. Laudisio, J. Singer, J.E. Fischer, and S. Kucheyev, Carbon, 2006 (in press).

[21] Z.G. Cambaz, G.N. Yushin, K.L. Vyshnyakova, L.N. Pereselentseva, and Y.G. Gogotsi, J. Am. Ceram. Soc, 2005, 89, 509. .

[22] J.Y. Lee, J. Li, and J. Jagiello, J. Solid State Chem., 2005, 178, 2527.

[23] J.Y. Lee, L. Pan, S.P. Kelly, J. Jagiello, T.J. Emge, and J. Li, Advanced Materials, 2005, 17, 2703.

[24] J.L.C. Rowsell and O.M. Yaghi, Angew. Chem. Int. Ed., 2005, 44, 4670.

[25] B. Chen, N.W. Ockwig, A.R. Millward, D.S. Contreras, and O.M. Yaghi, Angew. Chem. Int. Ed., 2005, 117, 4745.

[26] R.F. Service, Science, 2004, 305, 958.

[27] P. Benard and R. Chahine, Langmuir, 2001, 17, 1950.

[28] E.B. Yeager, J.A. Molla, and S. Gupta, in Proc. Electrochemical Society Symposium on the Electrochemistry of Carbon, Vol. 85-7, (Eds: J.R. Akridge and B. Schumm), Electrochemical Society, Pennington, NJ, 1984, 123.

[29] T. Yildrim and S. Ciraci, Phys. Rev. Lett. 2005, 94, 175501.

[30] O. Maresca, R. J.-M. Pellenq, F. Marinelli and J. Conard, J. of Chem. Phys., 2004, 121,12548 .

[31] J. Jagiello and M. Thommes, Carbon, 2004, 42, 1227.

[32] D.A. Ersoy, M.J. McNallan, and Y. Gogotsi, Mat. Res. Innovat., 2001, 5, 55.

[33] P.I. Ravikovitch and A.V. Neimark, Characterization of Nanoporous Materials from Adsorption and Desorption Isotherms. Colloids and Surfaces, 2001. 187188: p. 11-21. 
[34] S.J. Gregg and K.S.W. Sing, "Adsorption, Surface Area and Porosity”, London: Academic Press, UK 1982, 42.

[35] S. Brunauer, P. Emmett, and E. Teller, J. of Am. Chem. Soc., 1938, 60, 309.

[36] S. Lowell and J.E. Schields, "Powder Surface Area and Porosity",Chapman \& Hall, New York, US 1998, 17.

[37] A. Magnus and R. Kieffer, Zeit. Fuer Anorganische u, Allgemeine Chemie, 1929, $179,215$.

[38] D.M. Ruthven, "Principles of Adsorption and Adsorption Processes", Wiley \& Sons, Inc., New York, NY, US 1984.

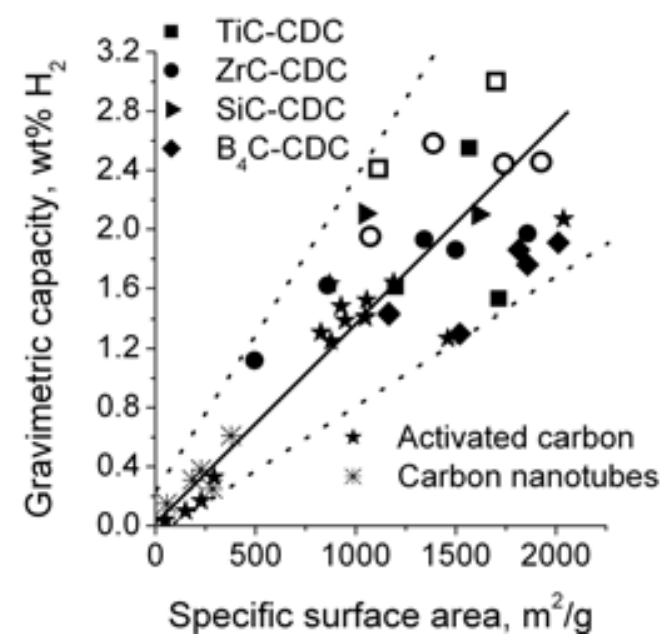

Fig. 1. Hydrogen uptake at $1 \mathrm{~atm}$ and $-196{ }^{\circ} \mathrm{C}$ for various porous carbon materials as a function of BET SSA. Solid symbols stands for as produced and hollow for hydrogen treated CDC. Hydrogen storage capacity generally increases with SSA. Solid line shows a linear fit with a slope of $\sim 1.1$ wt. $\%$ per $1000 \mathrm{~m}^{2} / \mathrm{g}$. Carbon nanomaterials having similar surface areas show large variations in hydrogen storage capacity. 


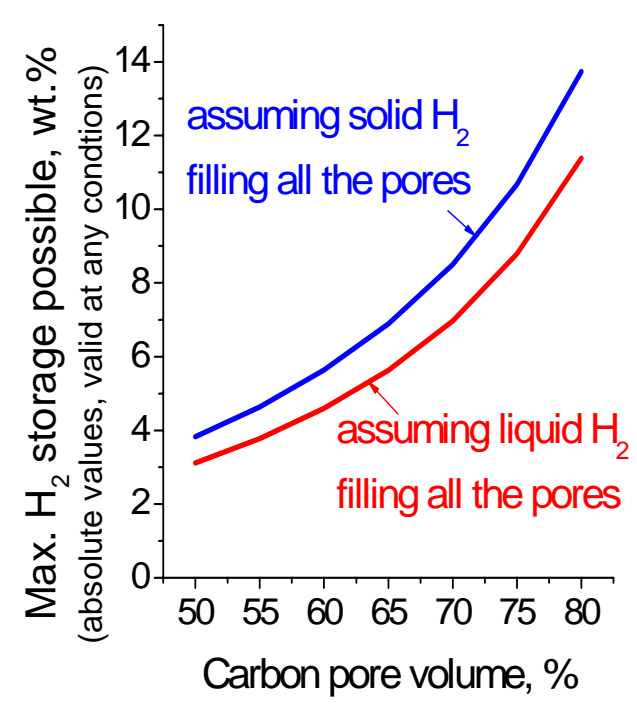

Fig. 2. Maximum possible hydrogen uptake for porous carbon materials as a function of carbon porosity. Pores are assumed to be fully filled either with solid (density $\approx$ $0.088 \mathrm{~g} / \mathrm{cc}$ ) or liquid (density $\approx 0.071 \mathrm{~g} / \mathrm{cc}$ ) hydrogen condensed on the carbon surface.
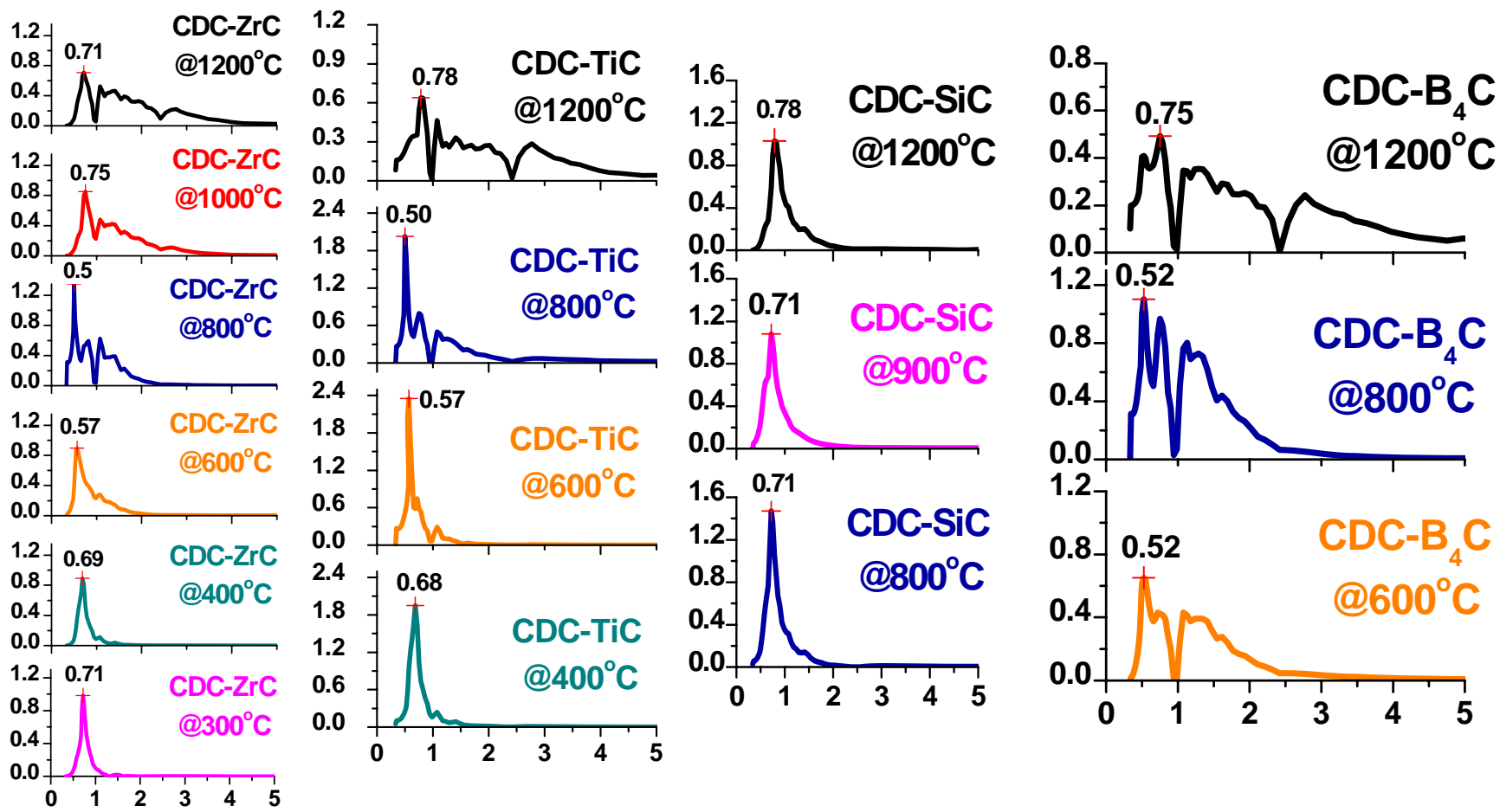

Fig. 3. Pore-size distributions of the CDCs as a function of synthesis temperature calculated using NLDFT. Minima at about 1 and $2.5 \mathrm{~nm}$ are artifacts of the DFT method. Synthesis temperature and average pore size are indicated in each graph. 


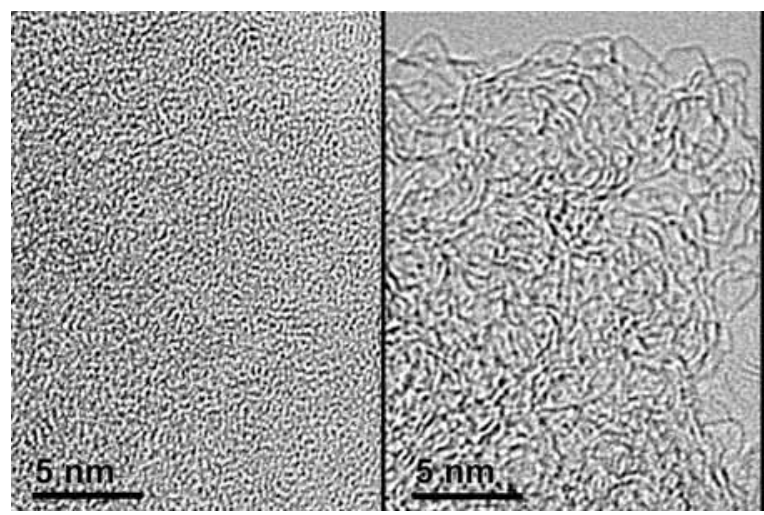

(a)

(b)

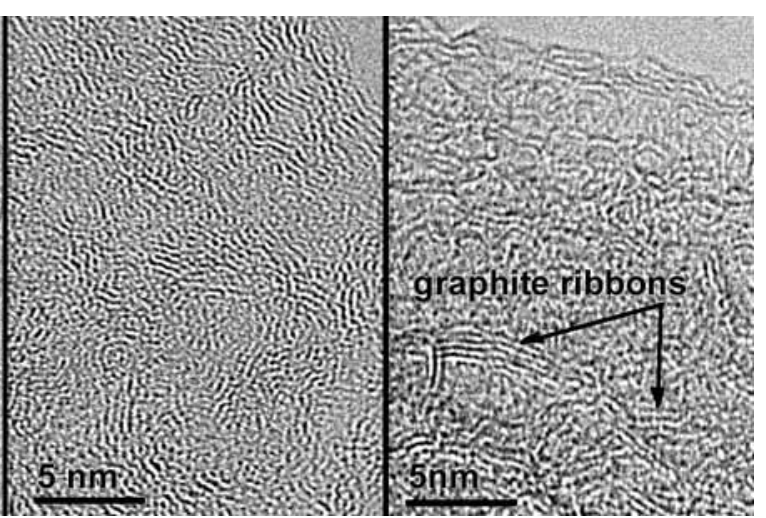

(c)

(d)

Fig. 4. TEM micrographs of the CDCs synthesized from TiC at 400 (a), 800 (b), 1000 (c), and $1200^{\circ} \mathrm{C}(\mathrm{d})$. Graduate structure evolution is observed as chlorination temperature increases.

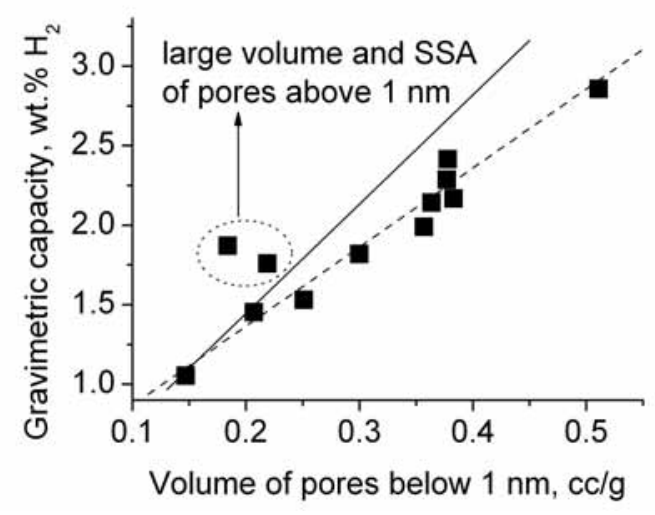

(a)

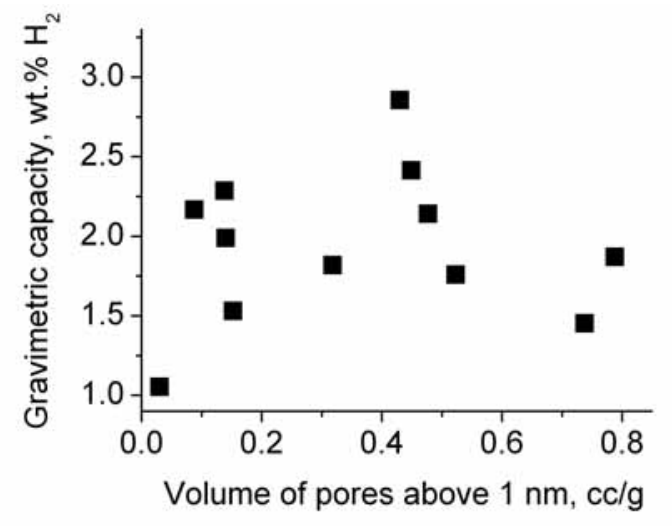

(c)

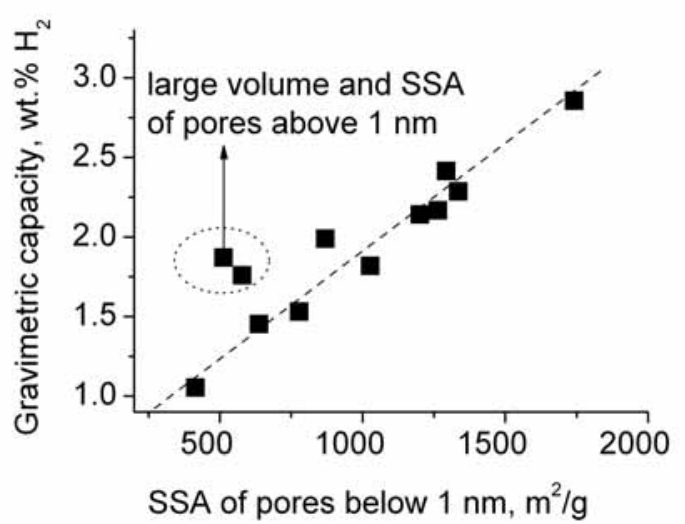

(b)

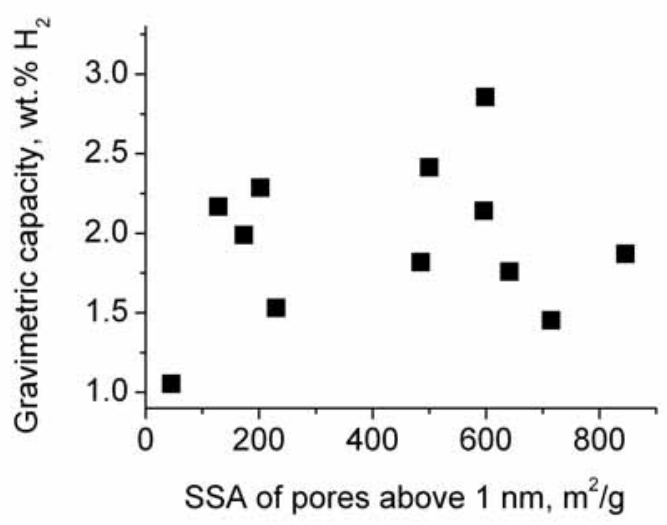

(d)

Fig. 5. Hydrogen uptake at $1 \mathrm{~atm}$ and $-196{ }^{\circ} \mathrm{C}$ versus volume and specific surface area of pores below $(a, b)$ and above $(c, d) 1 \mathrm{~nm}$. While larger volume of smaller pores was seen to increase hydrogen storage almost linearly, no correlations were found between the volume or surface area of larger pores and hydrogen capacity of CDCs. Solid line in (a) corresponds to the maximum amount of $\mathrm{H}_{2}$ that could be stored in pores $<1 \mathrm{~nm}$, assuming $\mathrm{H}_{2}$ density $=0.071 \mathrm{~g} / \mathrm{cc}$ (liquid $\mathrm{H}_{2}$ density). SSA was calculated using NLDFT method. 


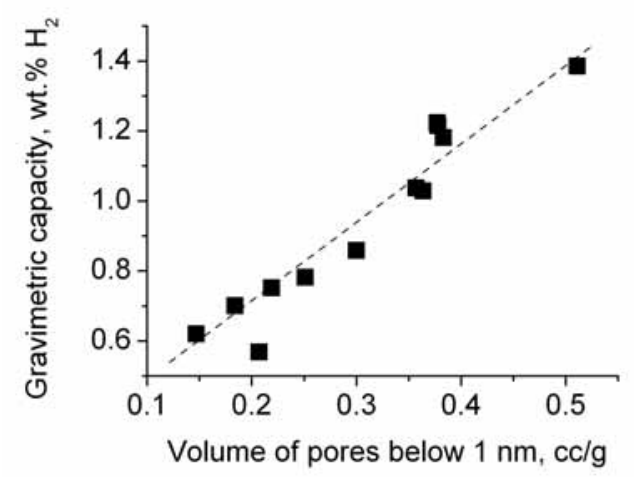

Fig. 6. Hydrogen uptake at $0.1 \mathrm{~atm}$ and $-196{ }^{\circ} \mathrm{C}$ as a function of volume of pores below $1 \mathrm{~nm}$.

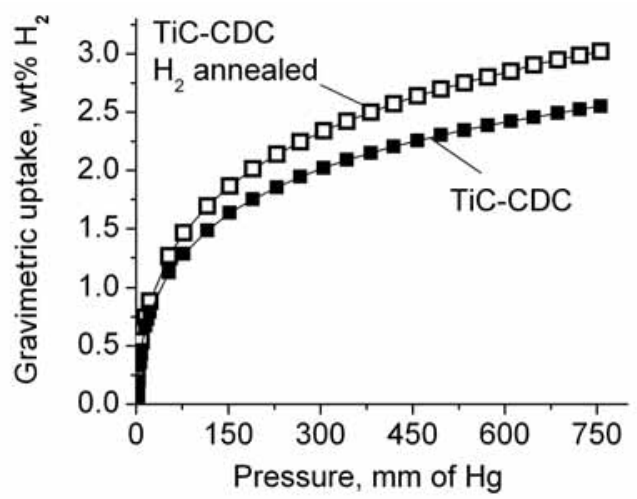

Fig. 7. Hydrogen sorption isotherms at $-196^{\circ} \mathrm{C}$. CDC produced from $\mathrm{TiC}$ at $800^{\circ} \mathrm{C}$ before and after two hours $\mathrm{H}_{2}$ annealing at $600^{\circ} \mathrm{C}$

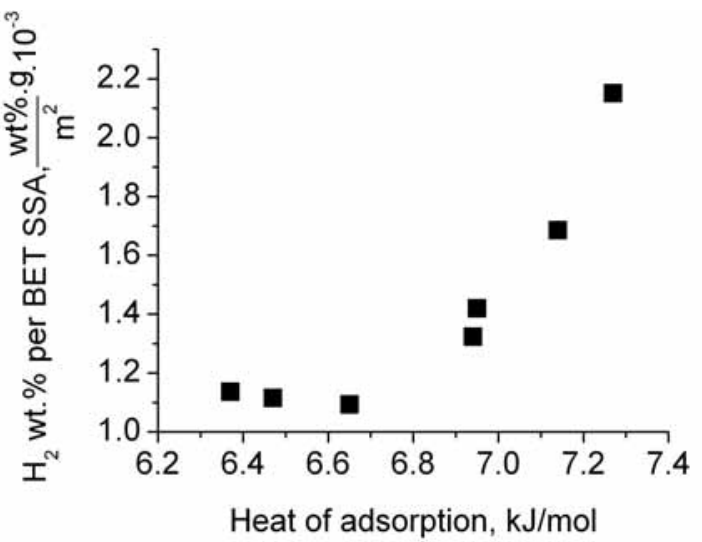

(a)

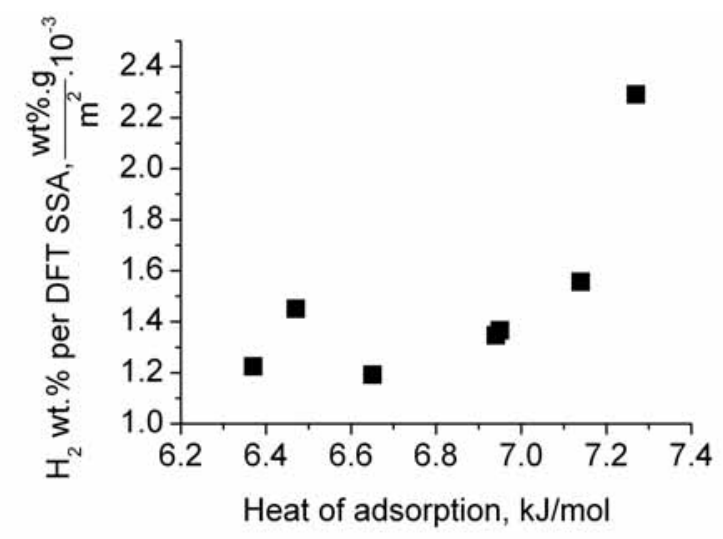

(b)

Fig. 8. Hydrogen uptake at 1 atm. and $-196{ }^{\circ} \mathrm{C}$ per (a) BET and (b) DFT surface area vs. the integrated average heat of adsorption. 


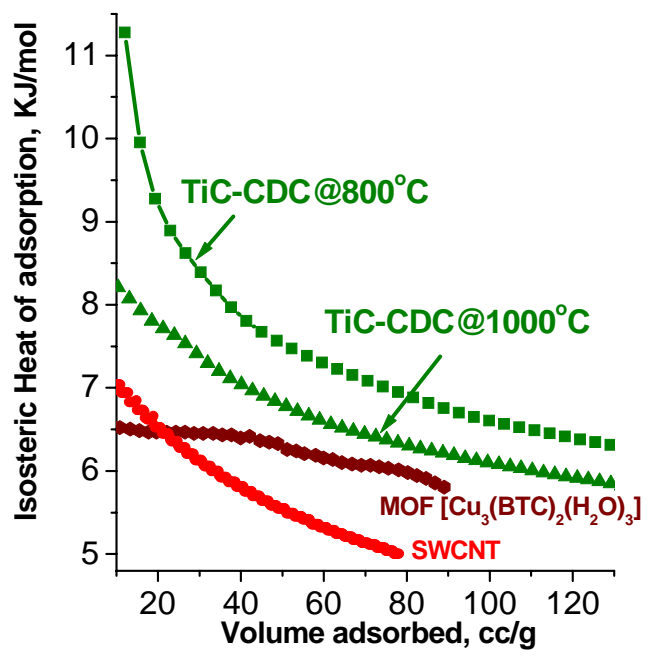

Fig. 9. Hydrogen heat of adsorption. $\mathrm{CDC}$ produced from $\mathrm{TiC}$ at $800^{\circ} \mathrm{C}$ and $1000^{\circ} \mathrm{C}$ compared to $\mathrm{MOF}\left(\mathrm{Cu}_{3}(\mathrm{BTC})_{2}\left(\mathrm{H}_{2} \mathrm{O}\right)_{3}\right)$ [21] and SWCNT. 